\title{
Prevalence and associated factors of stunting among primary school children in Eastern Ethiopia
}

\author{
This article was published in the following Dove Press journal: \\ Nutrition and Dietary Supplements \\ 18 Septermber 2015 \\ Number of times this article has been viewed
}

Firehiwot Mesfin'

Yemane Berhane ${ }^{2}$

Alemayehu Worku ${ }^{2,3}$

'Department of Public Health, College of Health and Medical Sciences, Haramaya University, Harar, Ethiopia; ${ }^{2}$ Addis Continental Institute of Public Health, ${ }^{3} \mathrm{School}$ of Public Health, Addis Ababa University, Addis Ababa, Ethiopia
Correspondence: Firehiwot Mesfin College of Health and Medical Sciences, Haramaya University, Po Box 235, Harar, Ethiopia

Email mfirehiwotm@gmail.com
Background: Stunting is a serious impediment to child survival and developing a full learning capacity. Despite several decades of efforts, stunting remained a major public health concern in Ethiopia. Thus, periodic assessment of the factors associated with stunting is imperative.

Methods: A cross-sectional study was conducted among school-age children in Eastern Ethiopia. Anthropometric measurements were taken according to the World Health Organization standard procedures. A child was identified as stunted if height-for-age $z$ score is $<-2$ standard deviations of the median of the reference population. A binary logistic regression model was used to identify factors associated with stunting. Clustering of stunting within schools was controlled during analysis using cluster option in STATA syntax.

Results: The prevalence of stunting among school-aged children was $8.9 \%$ (95\% confidence interval [CI]: 7.6-10.3); of which $2 \%$ had severe stunting. The risk of stunting was 1.71 times greater for children born to working mothers than those born to housewives (adjusted odds ratio $[\mathrm{AOR}]=1.71 ; 95 \% \mathrm{CI}: 1.08-2.72$ ). Those children whose families did not use a bed net in their home were 1.76 times more likely to be stunted as children than those whose families used insecticide-treated nets ( $\mathrm{AOR}=1.76 ; 95 \% \mathrm{CI}$ : 1.22-2.52). Moreover, the risk of stunting was 1.59 times greater for children who had suffered from illness within the last 2 weeks than children who were apparently healthy ( $\mathrm{AOR}=1.59 ; 95 \% \mathrm{CI}: 1.04-2.40)$. On the other hand, the risk of stunting was $30 \%$ lower for children born to an older mother than a younger one.

Conclusion: Stunting, which is indicative of chronic malnutrition, was $8.9 \%$ among schoolaged children in Kersa, Ethiopia. It was associated with maternal working status, maternal age, child morbidity status, and not using insecticide-treated nets at the household level. Nutrition programs that focus on improving childhood nutrition and promoting linear growth, conducting focused public education to increase the use of mosquito net, will benefit children.

Keywords: stunting, anthropometry, school children, Kersa, Ethiopia

\section{Introduction}

Malnutrition is a major public health concern affecting a significant number of schoolage children influencing their health, growth and development, and academic school performance. ${ }^{1}$ Stunting (low height-for-age) is acknowledged as the best indicator for child growth that indicates chronic undernutrition. ${ }^{2}$ Children who are stunted have a reduced learning ability in school and poor scholastic achievement, ${ }^{3}$ are more likely to repeat grades in school or drop out, ${ }^{4}$ and could increase the risk that they do not complete primary or secondary education.

Stunted children do not reach their full growth potential and become stunted adolescents and adults. The functional consequences of stunting continue in adulthood, with 
reduced work capacity and, in women, increased risk of mortality during childbirth and adverse birth outcomes. ${ }^{5}$

According to the Growth and Assessment Surveillance Unit of the World Health Organization (WHO) 2010, the global prevalence of malnutrition among school-aged children (5-14 years old), as indicated by the prevalence of stunting, was approximately $28 \%$ (171 million children), with Eastern Africa suffering a higher rate of $45 \%{ }^{6}$ In Ethiopia, previous studies from different regions showed that the prevalence of stunting ranges from $9.8 \%$ to $48.1 \%$ among school children, which indicated that undernutrition is a public health problem. ${ }^{7,8}$

Child stunting is a result of long-term chronic consumption of a low-quality diet in combination with morbidity, infectious diseases, and environmental problems. ${ }^{9}$ It is a lifelong condition that results from long-term nutritional deprivation that can occur both pre- and postnatally, inadequate child care, poor environmental, and sociocultural conditions. $^{10}$

In many developing countries, particularly in Africa, tradition has laid the responsibility of child care on women, which begins at conception and continues until infancy, teenage, and adulthood. ${ }^{11}$ Maternal employment causes children's nutrition outcomes to be better ${ }^{8}$ or worse. ${ }^{12}$ It has potential implications virtually for all aspects of children's growth and development, and nutrition outcomes are no exception. The quality of children's diets and their subsequent physical health may depend significantly on whether and how much their mothers work outside the home for additional income they bring into the household may help to ensure a stable supply of good quality food. On the other hand, employed mothers may have less time available to supervise their children's activities and to prepare their meals. ${ }^{13}$

Nutritional assessments among school children and adolescents are important as they constitute a potentially susceptible group. Growth assessment is an important tool for monitoring health and nutritional status of children, identifying deviations from normality, and also providing an indirect measurement of well-being for the entire population. ${ }^{14}$ The internationally recommended way to assess malnutrition at a population level is to take body or anthropometric measurements. ${ }^{15}$

Although malnutrition is a public health problem in Ethiopia, there is little documented information on the nutritional status of school children and adolescents from Eastern Ethiopia. It is only recently the Ministry of Education of Ethiopia recognizes the impact that poor health and nutrition can have on children's ability to learn, on their school attendance, and on concentration and developed National School Health and Nutrition Strategy (2012) for gearing the younger generation toward better working potential and productivity, equipping students with the necessary knowledge including health and nutrition. ${ }^{16}$

Therefore, using the anthropometric index, the objective of this study was to investigate the prevalence of stunting and associated factors among school children aged 5-14 years living in Kersa district, Ethiopia.

\section{Methods}

This cross-sectional study was conducted among school children aged 5-14 years in 12 public primary schools of Kersa district, East Hararge Zone, Oromia regional state, and Eastern Ethiopia. Kersa district is one of the districts in the zone and comprises 38 kebeles (the smallest administrative units) in Ethiopia. Kersa Demographic Surveillance and Health Research Center (KDS-HRC) comprises 10,256 households and a total population of 48,192 . The demographic surveillance systems has three climatic zones, lowland, highland, and midland, and stratified as ten rural kebeles and two semi-urban areas. In all study sites, there are health extension workers or community health workers who provide basic primary health care services. Moreover, there are only three health centers within the geographic coverage of the demographic surveillance systems, but there is no hospital. The health care coverage of the district was $80 \%$ in 2010 . According to the Office of Education in Kersa district, there were 18 elementary, two secondary, one preparatory, and two religious schools in the study Kebeles. The livelihood of the study population is mainly dependent on subsistence agriculture. But small trade, government employment, and daily work are also means of living. The district is known by its scarce crop, roots, and other vegetables production. Subsistent crops are often planted during the wet season (June-September) and harvested during the dry season (October-February). There are no profound cultural taboos related to eating habits. The survey was conducted during January-February 2012.

The study population was a student-parent pair; students were identified in schools and their parents were contacted through the demographic surveillance system operating around the schools selected for the study. The calculated sample size was 1,988 assuming a stunting prevalence of $27 \%$ at a $95 \%$ confidence interval and a margin of error of $2 .^{7}$ A $10 \%$ nonresponse rate was added to the sample size as a contingency. 
In each school, a sampling frame was prepared from the student roster in each grade, and students were selected from each grade by a simple random sampling method proportional to the student size. All schools involved in this study were located within the geographic limit of the Demographic and Health Surveillance (KDH-HRC) site which is managed by Haramaya University (the host of the principal investigator). Thus, parents were contacted through the surveillance field workers.

\section{Data collection}

Data were collected using a pretested structured questionnaire translated into the local language (Afan Oromo) by trained and experienced data collectors who were fluent in the local language. The data collection tool was prepared based on the national survey questionnaire. ${ }^{17}$ Respondents of the questionnaire were parents/caregivers of the children identified in the study schools. After students were randomly selected from the schools, their household number was traced in the KDH-HRC database. Then, data collectors visited the children's house to administer the questionnaire to one of the parents/caretakers. A unique identifier was given to link the children anthropometric measurement and household characteristics.

\section{Anthropometric measurements}

The age of the children was derived from the school register. To assess the nutritional status of students, height was measured according to the WHO standard procedures. ${ }^{10,15}$ Individual height was measured to the nearest $0.1 \mathrm{~cm}$ with a locally manufactured wooden stadiometers with a sliding headpiece. The subject stood on the basal part of the device with feet together. The shoulders, the buttocks, and the heels had to touch the vertical measuring board. The children stood with their eyes in the Frankfort horizontal plane.

Information about night-blindness was collected by asking the mothers regarding the status of the child in seeing at dusk or in dim light. In addition, mothers/caretakers were asked about whether the child was sick and treated during the previous 15 days before the survey.

\section{Dietary intake assessment}

Food consumption habit of the children was investigated by a semiquantitative food frequency questionnaire (FFQ) consisting of foods commonly consumed by the study population. The FFQ consisted 25 items of foods grouped into seven as cereals, legumes, meat, egg, vegetables, fruits, and dairy products. The interview to obtain information how often specific types of food, such as vegetables, fruit, legumes, and milk, were given per week (eg, daily, three to five times per week, less than three times per week, or never) was done through the parents in the presence of their children.

To ensure data quality, training of data collection team, standardization of measurements, pretesting of procedures and materials, and field monitoring of data collection were done. Timely availability of the study instruments, meeting of data collection team at the end of every day to share experiences and submit completed forms, and solving field problems were ensured.

Based on the United Nations Children's Fund's conceptual framework for the causes of child malnutrition and from previous studies, ${ }^{7,18,19}$ the independent variables included in the study were the child's age, sex, morbidity status, the number of children in the household, residence, educational status and occupation of parents, age of the mother, availability of toilet, water source, and waste disposal system of the household.

\section{Statistical analysis}

The data were double entered using the EpiData 3.1 software by trained data clerks and analyzed using STATA version 11 Descriptive statistics (frequency counts and percentages) were used to summarize categorical variables, whereas mean and standard deviations (SDs) were used to present continuous variables. A logistic regression model was employed to ascertain any significant association between independent variables and dependent variables. Correlation among students within school was controlled during the analysis using cluster option of STATA command. Based on the knowledge of United Nations Children's Fund's conceptual framework for the causes of child malnutrition ${ }^{20,21}$ and previous studies, ${ }^{7,18,19}$ logistic regression models were constructed to categorize the risk factors of malnutrition among school-age children. The variables that showed an association with the outcome variable at the bivariate analysis and the variables with $P$-value $\leq 0.2$ were entered into the final multivariable logistic regression model. However, age and sex, considered as biologically relevant and not influenced by other factors, but can be determinants over the rest, were entered into the model regardless of the $P$-value. The odds ratio along with the $95 \%$ confidence interval (CI) was estimated to assess the strength of the association and a $P$-value $<0.05$ was considered as statistically significant in the multivariable analysis.

The $z$ score values for height-for-age were calculated using the WHO AnthroPlus software. ${ }^{22}$ Calculated $z$ scores 
of height-for-age (HAZ) were then used to classify the level of stunting using the WHO new reference values for school boys and girls. ${ }^{15}$ Children whose HAZ $<-2$ SDs of the median of the reference population were considered chronically malnourished or stunted.

Ethical clearance was obtained from the College of Health Science of Haramaya University. An anthropometric measurement was performed after obtaining a signed written informed consent from parents and an oral assent from the children. Privacy and confidentiality were maintained at each step of the study process.

\section{Results}

\section{Demographic characteristics of the students}

A total of 1,768 school children (5-14 years) participated in the study (participation rate $=89 \%$ ). The male-female ratio was 1.34 with $57.3 \%$ boys and $42.7 \%$ girls. The mean age of school children was 10.7 years ( $\mathrm{SD} \pm 2.1$ ). Most of the children (45.4\%) were early adolescent $10-12$ years, whereas $30.6 \%$ were preadolescents 5-9 years. Fifty-eight percent of the children were from the mother with an age group of 24-34 years and the average age of mothers was 36.2 years with SDs of \pm 7.6 . In all, $84 \%$ children were rural and $16 \%$ were from semi-urban. In all, $68 \%$ of the fathers and $78 \%$ of the mothers were illiterate. It was found that a majority of children (93.4\%) belonged to nonworking mothers and only $6.6 \%$ belonged to working mothers. Most children (77.1\%) came from families with more than four children, and $22.9 \%$ children were from families with less than four children (Table 1).

\section{Nutritional status of school children}

Mean (SD) HAZ was - 0.19 (1.4). The prevalence of stunting was $8.9 \%$ (95\% CI: 7.6-10.3), while severe stunting ( $<-3 \mathrm{SD}$ of HAZ) was identified in $2 \%(95 \% \mathrm{CI}: 1.3-2.7)$ of the children. Among the girls, 70 (9.3\%) were stunted as compared to 87 boys $(8.6 \%)(P=0.57)$. Stunting seemed more prevalent among children aged $13-14$ years $(11.3 \%)$ as compared to children aged 5-9 years (7.2\%). This trend was not statistically significant. Among children who had suffered from illness within the last 2 weeks, $11.7 \%$ of them were stunted. The prevalence of stunting among children in educated mothers (12.4\%) was higher than those children born to illiterate mothers $(8.2 \%)$. Moreover, the level of stunting was lower $(8.6 \%)$ among children whose mothers were housewives, but higher (16.2\%) among children whose mothers were working. This difference was statistically significant (Table 2).
Table I Sociodemographic and other selected characteristics of primary school children and their parents, Kersa District, Eastern Ethiopia, 2012

\begin{tabular}{|c|c|c|}
\hline Variable & Number & $\%$ \\
\hline \multicolumn{3}{|l|}{ Child age $(n=1,768)$} \\
\hline $5-9$ years & 541 & 30.6 \\
\hline $10-12$ years & 802 & 45.4 \\
\hline $13-14$ years & 425 & 24.0 \\
\hline \multicolumn{3}{|l|}{ Child sex $(n=I, 768)$} \\
\hline Female & 755 & 42.7 \\
\hline Male & 1,013 & 57.3 \\
\hline \multicolumn{3}{|l|}{ Residence $(n=I, 768)$} \\
\hline Rural & $\mathrm{I}, 479$ & 83.7 \\
\hline Semi-urban & 289 & 16.3 \\
\hline \multicolumn{3}{|c|}{ Father's education $(n=I, 6 \mid I)$} \\
\hline Illiterate/read-write & 1,135 & 68.8 \\
\hline Primary & 384 & 23.3 \\
\hline Secondary and above & 130 & 7.9 \\
\hline \multicolumn{3}{|c|}{ Father's occupation $(n=1,649)$} \\
\hline Farmer & $\mathrm{I}, 407$ & 85.3 \\
\hline Working & 242 & 14.7 \\
\hline \multicolumn{3}{|l|}{ Maternal age $(n=I, 592)$} \\
\hline $24-34$ years & 925 & 58.1 \\
\hline$\geq 35$ years & 328 & 41.9 \\
\hline \multicolumn{3}{|c|}{ Mother's education $(n=I, 592)$} \\
\hline Illiterate/read-write & $\mathrm{I}, 244$ & 78.1 \\
\hline Literate & 348 & 21.9 \\
\hline \multicolumn{3}{|c|}{ Mother's occupation $(n=1,592)$} \\
\hline Housewife & $\mathrm{I}, 487$ & 93.4 \\
\hline Working & 105 & 6.6 \\
\hline \multicolumn{3}{|c|}{ Number of living children $(n=1,768)$} \\
\hline$<4$ & 404 & 22.9 \\
\hline$\geq 4$ & $\mathrm{I}, 364$ & 77.1 \\
\hline \multicolumn{3}{|l|}{ Wealth status } \\
\hline Poor & 724 & 41.0 \\
\hline Middle & 548 & 31.03 \\
\hline Rich & 494 & 27.97 \\
\hline \multicolumn{3}{|c|}{ Child illness in the last 2 weeks $(n=1,768)$} \\
\hline No & $\mathrm{I}, 605$ & 90.8 \\
\hline Yes & 163 & 9.2 \\
\hline \multicolumn{3}{|l|}{ Night-blindness $(n=I, 768)$} \\
\hline No & 1,595 & 90.2 \\
\hline Yes & 173 & 9.8 \\
\hline \multicolumn{3}{|l|}{ Water source $(n=I, 768)$} \\
\hline Safe source & 1,330 & 75.2 \\
\hline Unsafe source & 437 & 24.8 \\
\hline \multicolumn{3}{|l|}{ Waste disposal $(n=I, 768)$} \\
\hline Proper & 409 & 23.5 \\
\hline Improper & 1,359 & 76.5 \\
\hline \multicolumn{3}{|c|}{ Latrine availability at $\mathrm{HH}(\mathrm{n}=1,768)$} \\
\hline Unimproved facility & 538 & 30.4 \\
\hline Improved facility & 1,230 & 69.6 \\
\hline \multicolumn{3}{|l|}{ ITNs usage } \\
\hline Yes & 1,096 & 61.9 \\
\hline No & 672 & 38.1 \\
\hline
\end{tabular}

Abbreviation: ITNs, insecticide-treated nets; $\mathrm{HH}$, household.

\section{Types of foods usually consumed/given to children}

According to the FFQ in the present study, almost all mothers/ caretakers $(99.4 \%)$ reported that they were usually including 
Table 2 Sociodemographic characteristics of children and their parents and other selected characteristics associated with stunting among school children at Kersa district, Eastern Ethiopia, 2012

\begin{tabular}{|c|c|c|c|}
\hline \multirow[t]{2}{*}{ Characteristics } & \multicolumn{2}{|l|}{ Stunting } & \multirow{2}{*}{$\begin{array}{l}\text { Crude OR } \\
(95 \% \mathrm{Cl})\end{array}$} \\
\hline & Stunted & Not stunted & \\
\hline \multicolumn{4}{|l|}{ Child age $(n=1,768)$} \\
\hline $5-9$ years & $39(7.2 \%)$ & $502(92.8 \%)$ & I \\
\hline $10-12$ years & $70(8.7 \%)$ & $732(91.3 \%)$ & $1.23(0.59-2.53)$ \\
\hline $13-14$ years & 48 (II.3\%) & $376(88.7 \%)$ & $\mathrm{I} .64(0.87-3.09)$ \\
\hline \multicolumn{4}{|l|}{ Maternal age $(n=1,590)$} \\
\hline $24-34$ years & 95 (10.3\%) & $829(89.7 \%)$ & I \\
\hline$\geq 35$ years & $50(7.5 \%)$ & $616(92.5 \%)$ & $0.71(0.48-1.04)$ \\
\hline \multicolumn{4}{|l|}{ Child sex $(n=I, 768)$} \\
\hline Female & $70(9.3 \%)$ & $685(90.6 \%)$ & I \\
\hline Male & $87(8.6 \%)$ & 925 (91.4\%) & $0.92(0.69-1.23)$ \\
\hline \multicolumn{4}{|l|}{ Residence $(n=I, 768)$} \\
\hline Rural & 122 (8.3\%) & I,356 (91.7\%) & I \\
\hline Semi-urban & 35 (12.1\%) & $254(87.9 \%)$ & $1.53(0.99-2.36)$ \\
\hline \multicolumn{4}{|c|}{ Father's education $(n=1,647)$} \\
\hline Illiterate/read-write & $100(8.8 \%)$ & I,033 (91.2\%) & I \\
\hline Primary & $31(8.1 \%)$ & $353(91.9 \%)$ & $0.91(0.62-1.31)$ \\
\hline $\begin{array}{l}\text { Secondary and } \\
\text { above }\end{array}$ & $17(13.1 \%)$ & II 3 (86.9\%) & I.55 (0.88-2.75) \\
\hline \multicolumn{4}{|c|}{ Mother's education $(n=1,590)$} \\
\hline Illiterate/read-write & $102(8.2 \%)$ & I, I 40 (9।.8\%) & I \\
\hline Literate & $43(12.4 \%)$ & $305(87.6 \%)$ & $1.57(1.04-2.38)$ \\
\hline \multicolumn{4}{|c|}{ Mother's occupation $(n=1,805)$} \\
\hline Housewife & $128(8.6 \%)$ & I,358 (9l.4\%) & I \\
\hline Working & 17 (16.2\%) & $88(83.8 \%)$ & $2.04(1.31-3.20)$ \\
\hline \multicolumn{4}{|c|}{ Father's occupation $(n=I, 649)$} \\
\hline Farmer & 117 (8.3\%) & I,289 (91.7\%) & 1 \\
\hline Working & $32(13.22 \%)$ & $210(86.78 \%)$ & $1.68(0.99-2.84)$ \\
\hline \multicolumn{4}{|c|}{ Number of children $(n=I, 768)$} \\
\hline$<4$ & $43(10.6 \%)$ & $36 \mid(89.4 \%)$ & I \\
\hline$\geq 4$ & II 4 (8.4\%) & I,249 (91.6\%) & $0.77(0.48-1.18)$ \\
\hline \multicolumn{4}{|l|}{ Wealth status } \\
\hline Poor & $65(8.9 \%)$ & 659 (91.02\%) & 1 \\
\hline Middle & $39(7.1 \%)$ & $509(92.9 \%)$ & $0.77(0.43-1.40)$ \\
\hline Rich & $53(10.8 \%)$ & 440 (89.2\%) & $1.22(0.80-1.86)$ \\
\hline \multicolumn{4}{|l|}{ Water source $(\mathrm{n}=\mathrm{I}, 768)$} \\
\hline Safe source & 112 (8.42\%) & I,218 (91.6\%) & 1 \\
\hline Unsafe source & $45(10.3 \%)$ & $392(89.7 \%)$ & I.25 (0.88-I.77) \\
\hline \multicolumn{4}{|c|}{ Waste disposal $(n=1,768)$} \\
\hline Proper & $39(9.5 \%)$ & $370(90.5 \%)$ & I \\
\hline Improper & 118 (8.7\%) & $\mathrm{I}, 240$ (9I.3\%) & $0.90(0.55-1.47)$ \\
\hline \multicolumn{4}{|l|}{ Toilet $(n=1,768)$} \\
\hline Improved facility & 115 (9.3\%) & I, I I 5 (90.7\%) & I \\
\hline Unimproved facility & $42(7.8 \%)$ & $495(92.2 \%)$ & $0.82(0.5 \mathrm{I}-\mathrm{I} .32)$ \\
\hline \multicolumn{4}{|l|}{ ITNs usage } \\
\hline Yes & 79 (7.21\%) & I,017 (92.79\%) & 1 \\
\hline No & $78(11.62 \%)$ & $593(88.38 \%)$ & $1.69(1.15-2.49)$ \\
\hline \multicolumn{4}{|c|}{ Child illness in the last 2 weeks $(1,768)$} \\
\hline No & 138 (8.6\%) & I,466 (9l.4\%) & I \\
\hline Yes & 19 (11.7\%) & $43(88.3 \%)$ & I.4I (0.93-2.14) \\
\hline \multicolumn{4}{|c|}{ Night-blindness $(n=\mid, 768)$} \\
\hline No & 146 (9.2\%) & ।,448 (90.8\%) & I \\
\hline Yes & II (6.4\%) & $162(93.6 \%)$ & $0.67(0.39-1.16)$ \\
\hline
\end{tabular}

Abbreviations: $\mathrm{Cl}$, confidence interval; ITNs, insecticide-treated nets; OR, odds ratio. starchy foods (cereals) and (70.6\%) legumes on their children's plate daily, while protein-rich foods (meat and egg) were consumed less frequently by most children. The number of children who were given fruit and vegetable was very low ( $12 \%$ and $57 \%$, respectively). The dietary habit was not statistically significant.

A multivariable logistic regression model was used to examine the effect of sociodemographic and other related factors on stunting. In the first logistic regression model, it was found that the children's nutritional status was significantly affected by maternal working status (AOR $=1.65 ; 95 \% \mathrm{CI}$ : $1.12-2.44$ ) and maternal education ( $\mathrm{AOR}=1.40 ; 95 \% \mathrm{CI}$ : $1.02-1.93)$. In the model II, not using insecticide-treated nets (ITNs) at the household level (AOR $=1.67 ; 95 \% \mathrm{CI}$ : 1.15-2.42) was significantly associated with stunting among the environmental factors, while in the model III, none of the variables were found significant (Table 3).

In the final model, child stunting was significantly related to the mothers' working status $(P<0.05)$. The risk of stunting was 1.71 times higher for children born to working mothers than those born to housewives ( $\mathrm{AOR}=1.71$; 95\% CI: 1.08-2.72). Those children whose families did not use a bed net in their home were 1.76 times more likely to be stunted as children from those families that use ITNs (AOR $=1.76 ;$ 95\% CI: 1.22-2.52) (Table 3). Moreover, the risk of stunting was 1.59 times greater for children who had suffered from illness within the last 2 weeks than children who were apparently healthy $(\mathrm{AOR}=1.59 ; 95 \%$ CI: 1.04-2.40). On the other hand, children being born to older mothers $\geq 35$ (AOR $=0.70 ; 95 \%$ CI: $0.50-0.99$ ) were found to be protective against stunting. The risk of stunting was $30 \%$ lower for children born to older mother than younger one (Table 3 ).

\section{Discussion}

Children stunted at school age are likely to have been exposed to poor nutrition since early childhood and the degree of stunting tends to increase throughout the school-age years. In this study, the prevalence of stunting was $8.9 \%$ which is similar to a study in Burkina Faso ${ }^{23}$ and Pakistan. ${ }^{24}$ However, the prevalence from this study is lower than the previous studies among school-aged children in different regions of Ethiopia. ${ }^{7,8,17,19,23}$ Similarly, it is lower than the range of stunting (24.5-77.3) obtained for children from African countries (Ghana, Nigeria, and Kenya). ${ }^{25-28}$ This may be attributed to the differences in socioeconomic, culture, feeding habits, environmental factors, and public service utilization of the community in the study area. 
Table 3 Results of multivariable logistic regression analysis for stunting among primary school children at Kersa district, Eastern Ethiopia, 2012

\begin{tabular}{|c|c|c|c|c|}
\hline Variable & $\begin{array}{l}\text { Model I } \\
\text { OR (Cl) }\end{array}$ & $\begin{array}{l}\text { Model II } \\
\text { OR (CI) }\end{array}$ & $\begin{array}{l}\text { Model III } \\
\text { OR (Cl) }\end{array}$ & $\begin{array}{l}\text { Final model } \\
\text { OR }(\mathrm{Cl})\end{array}$ \\
\hline \multicolumn{5}{|l|}{ Maternal age } \\
\hline 24-34 years & I & & & I \\
\hline$\geq 35$ years & $0.71(0.49-1.03)$ & & & $0.70(0.50-0.99)$ \\
\hline \multicolumn{5}{|l|}{ Father's occupation } \\
\hline Farmer & I & & & I \\
\hline Working & $\mathrm{I} .67(0.79-3.5 \mathrm{I})$ & & & $1.73(0.82-3.62)$ \\
\hline \multicolumn{5}{|l|}{ Father's education } \\
\hline Illiterate/read-write & I & & & I \\
\hline Primary & $0.76(0.79-1.33)$ & & & $0.8 I(0.58-I .12)$ \\
\hline Secondary and above & $0.71(0.39-1.28)$ & & & $0.74(0.38-1.42)$ \\
\hline \multicolumn{5}{|l|}{ Mother's education } \\
\hline Illiterate/read-write & I & & & I \\
\hline Literate & $1.40(1.02-1.93)$ & & & $1.19(0.8 \mathrm{I}-1.78)$ \\
\hline \multicolumn{5}{|l|}{ Mother's occupation } \\
\hline Housewife & I & & & I \\
\hline Working & $1.65(1.12-2.44)$ & & & I.7। (I.08-2.72) \\
\hline \multicolumn{5}{|l|}{ Residence } \\
\hline Rural & I & & & I \\
\hline Semi-urban & $0.92(0.49-1.69)$ & & & I.I I (0.55-2.22) \\
\hline \multicolumn{5}{|l|}{ Water source } \\
\hline Safe source & & I & & I \\
\hline Unsafe source & & $1.17(0.88-1.55)$ & & $1.36(0.98-1.91)$ \\
\hline \multicolumn{5}{|l|}{ ITNs usage } \\
\hline Yes & & I & & I \\
\hline No & & $1.67(1.15-2.42)$ & & $1.76(1.22-2.52)$ \\
\hline \multicolumn{5}{|l|}{ Child age } \\
\hline 5-9 years & & & I & I \\
\hline $10-12$ years & & & $1.27(0.59-2.68)$ & $1.29(0.59-2.85)$ \\
\hline $13-14$ years & & & $1.67(0.87-3.21)$ & $1.76(0.83-3.76)$ \\
\hline \multicolumn{5}{|l|}{ Child sex } \\
\hline Female & & & 1 & I \\
\hline Male & & & $0.90(0.67-1.22)$ & $0.97(0.78-1.20)$ \\
\hline \multicolumn{5}{|c|}{ Child illness in the last 2 weeks } \\
\hline No & & & I & I \\
\hline Yes & & & $1.55(0.93-2.28)$ & $1.59(1.04-2.40)$ \\
\hline \multicolumn{5}{|l|}{ Night-blindness } \\
\hline No & & & I & I \\
\hline Yes & & & $0.66(0.37-1.18)$ & $0.68(0.38-1.42)$ \\
\hline
\end{tabular}

Abbreviations: $\mathrm{Cl}$, confidence interval; ITNs, insecticide-treated nets; OR, odds ratio.

In this study, it was observed that children of working mothers were more likely to develop stunting than children whose mothers were housewives. This result can be explained by a decreased time of working mother to care for her child at early childhood may affect the feeding practice that adversely affects the linear growth. Stunting that occurred during early childhood may progress into school age. This finding is in agreement with previous study findings that stated children of nonworking mothers have better nutritional status than children of working mothers. ${ }^{11,12,29,30}$ However, one study from India reported the lack of a significant relationship between the working status of mothers and the prevalence of malnutrition in their children. ${ }^{31}$

Moreover, studies identified that children of educated mothers have better or worse nutrition outcomes regardless of the cause. ${ }^{13,35}$ In the present study, maternal education has showed a significant association with stunting in the model I although the difference is no longer significant in the final multivariable analysis. Children of literate mothers were more likely to be stunted than children of mothers with no formal education. This can be due to the fact that educated mothers were more likely to be employed to raise the household income and thus reduce time of child care. This finding might 
be in contrary to the previous research findings that showed children with more educated mothers were less likely to develop nutritional problems than those with less educated mothers, ${ }^{36,37}$ which can be explained as literate mothers adopt better caring practices for children, allocate family resources for nutrition, and have health decision-making power which ultimately affect the nutritional status of the children. ${ }^{38}$

In the present study, children of older mothers (aged $\geq 35$ years) had a lower prevalence of stunting than children whose mothers were younger. The decreased level of stunting in children of older mothers may be related to maternal experience and adequate child care at early childhood. ${ }^{32,33}$ Maternal age has also been documented in other studies in the developing world as an important risk factor for child malnutrition. ${ }^{34-36}$

In this study, stunting was statistically associated with children who had illness (cough, fever, and diarrhea) in the last 2 weeks. This finding can be explained by the fact that nutritional inadequacies causing stunting also impair host immunity, in turn, leaving them more vulnerable to recurrent infections and disease. ${ }^{37}$ Similarly, previous studies revealed that children with stunting were more likely to suffer from infections than children with good nutritional status. ${ }^{26,38}$

This study found that children from households do not own and uses ITNs were more likely to be stunted. This is likely to be a result of low awareness about ITNs utilization and not following a continuous health education provided at health facilities and community level to reduce malaria infections. The impact of ITNs on malaria control has been sufficiently documented. ${ }^{39}$

In the study area, the proportion of households that own long-lasting insecticide nets was $65.5 \%$ but only about one-third of ITNs-owned households are actually using for protection against mosquito bite. ${ }^{40}$ Since the district is recognized as malaria endemic and fringe zone ${ }^{41}$ a majority of the residents are at a higher risk of mosquito bite and of acquiring malaria infection.

A number of studies have indicated a deleterious effect of malaria on nutritional status. The direction of this association appears to be two-way, with malaria leading to compromised nutritional status and compromised nutritional status increasing susceptibility to malaria infection. ${ }^{42,43}$

Some limitations of the study could be the information about age of the children that was obtained from school records might be underestimated. This may incur some information bias that may have impact on the estimates of anthropometric indicators. Efforts were made to cross-check the recorded age by asking the parents and some of the children.

\section{Conclusion}

Stunting, which is an indicative of chronic malnutrition, was $8.9 \%$ among school-aged children in Kersa. The risk of stunting is high among children of working mothers, children who had illness in the last 2 weeks, and those whose families did not use ITNs.

In the future we recommend Nutrition programs that focus on improving childhood nutrition and promoting linear growth, improving the knowledge on the variety and amounts of foods young children should be fed to support healthy growth and development. Conducting focused public education to promote hand washing or hygiene practices and increase the use of mosquito net will benefit children.

\section{Acknowledgments}

The study was financially supported by grants from Haramaya University, Ethiopia. We thank all the children and their families, school headmasters from Kersa district and many people who assisted this study.

\section{Author contributions}

$\mathrm{FM}, \mathrm{YB}$, and AW contributed toward data analysis, drafting and critically revising the paper, and agree to be accountable for all aspects of the work.

\section{Disclosure}

The authors report no conflicts of interest in this work.

\section{References}

1. Standing Committee Nutrition. School age children their health and nutrition. SCN News; 2002:1-78.

2. Partnership for Child Development. School-age children, their nutrition and health. Department of Infectious Disease Epidemiology; 2002.

3. Council on Hemispheric Affairs. The Cost of Hunger in Ethiopia: The Social and Economic Impact of Child Undernutrition in Ethiopia. Implications for the Growth and Transformation of Ethiopia. Washington, DC: Council on Hemispheric Affairs; 2013.

4. Galal OM, Neumann CG, Hulett J. Proceedings of the International Workshop on Articulating the Impact of Nutritional Deficits on the Education for All Agenda. February 18-20, 2004, Los Angeles, California, USA. Food Nutr Bull. 2005;26(2 Suppl 2):S127-S287.

5. Best C, Neufingerl N, van Geel L, van den Briel T, Osendarp S. The nutritional status of school-aged children: why should we care? Food Nutr Bull. 2010;31(3):400-417.

6. de Onis M, Blossner M, Borghi E. Prevalence and Trends of Stunting Among Pre-school Children, 1990-2020. Geneva: Department of Nutrition for Health and Development, World Health Organization; 2011: 1-7.

7. Worku N, Erko B, Torben W, et al. Malnutrition and intestinal parasitic infections in school children of Gondar, North West Ethiopia. Ethiop Med J. 2009;47(1):9-16.

8. Zelellw D, Gebreigziabher BG, Alene KA, Negatie BA, Kasahune TA. Prevalence and associated factors of stunting among schoolchildren, in Debre Markos Town and Gozamen Woreda, East Gojjam Zone, Amhara Regional State, Ethiopia. J Nutr Food Sci. 2014;S8:007. 
9. World Health Organization. Childhood Stunting: Challenges and Opportunities. Report of a promoting healthy growth and preventing childhood stunting colloquium. Geneva: World Health Organization; 2014.

10. de Onis M, Onyango AW, Borghi E, Siyam A, Nishida C, Siekmann J. Development of a WHO growth reference for school-aged children and adolescents. Bull World Health Org. 2007;85(9):660-667.

11. Obiakor-Okeke PN. Anthropometric indices of primary school children from different socio-economic classes in Owerri Municipal. Eur J Prev Med. 2014;2(5):63-68.

12. Crepinsek MK, Burstein NR. Maternal Employment and Children's Nutrition: Electronic Publications from the Food Assistance and Nutritional Research Program. Cambridge, MA: Abt Associates Inc.; 2004.

13. Wang C, Kane RL, Xu D, et al. Maternal education and micro-geographic disparities in nutritional status among school-aged children in rural Northwestern China. PLoS One. 2013;8(12):e82500.

14. World Health Organization. Physical Status. The Use and Interpretation of Anthropometry. Technical Report Series No 854. Geneva: World Health Organization; 1995.

15. WHO Multicentre Growth Reference Study Group. WHO Child Growth Standards: length/height-for-age, weight-for-age, weight-for-length, weight-for-height and body mass index-for-age: methods and development; 2006. Available from: http://www.who.int/childgrowth/standards/ Technical_report.pdf.

16. Ministry of Education. National School Health and Nutrition Strategy. Addis Ababa: Ministry of Education; 2012.

17. Mekonnen H, Tadesse T, Kisi T. Malnutrition and its correlates among rural primary school children of Fogera District, Northwest Ethiopia. J Nutr Disord Ther. 2013;S12:002.

18. Audrie L, Benjamin F. Household environmental conditions are associated with enteropathy and impaired growth in rural Bangladesh. Am J Trop Med Hyg. 2013.

19. Reji P, Belay G, Erko B, Legesse M, Belay M. Intestinal parasitic infections and malnutrition amongst first-cycle primary schoolchildren in Adama, Ethiopia. Afr J Prim Health Care Fam Med. 2011;3(1):198.

20. UNICEF. The state of the world's children: malnutrition: causes, consequences and solutions. Nutr Rev. 1998; 56(4 Pt 1):115-123.

21. Victora CG, Huttly SR, Fuchs SC, Olinto MT. The role of conceptual frameworks in epidemiological analysis: a hierarchical approach. Int $J$ Epidemiol. 1997;26(1):224-227.

22. World Health Organization (WHO). WHO AnthroPlus for Personal Computers Manual: Software for Assessing Growth of the World's Children and Adolescents. Geneva: WHO; 2009.

23. Daboné C, Delisle H, Receveur O. Poor nutritional status of schoolchildren in urban and peri-urban areas of Ouagadougou (Burkina Faso). Nutr J. 2011;10:34.

24. Mushtaq M, Gull S, Khurshid U, Shahid U, Shad MA, Siddiquil AM. Prevalence and socio-demographic correlates of stunting and thinness among Pakistani primary school children. BMC Public Health. 2011;11:790.

25. Angelina OD, Adwoa NA, Clara O-O. Nutritional status of upper primary school pupils in a rural setting in Ghana. Int $J$ Nutr Food Sci. 2013;2(6):320-326.

26. Goon DT, Toriola AL, Shaw BS, et al. Anthropometrically determined nutritional status of urban primary schoolchildren in Makurdi, Nigeria. BMC Public Health. 2011;11:769.

Nutrition and Dietary Supplements

\section{Publish your work in this journal}

Nutrition and Dietary Supplements is an international, peer-reviewed, open access journal focusing on research into nutritional requirements in health and disease, impact on metabolism and the identification and optimal use of dietary strategies and supplements necessary for normal growth and development. The journal welcomes papers covering

Submit your manuscript here: http://www.dovepress.com/nutrition-and-dietary-supplements-journal
27. Akor F, Seline O, Angela O. Nutritional status of newly enrolled primary school children in Jos-Plateau, Nigeria. Pak J Nutr. 2010;9(12): $1166-1170$

28. Mwaniki E, Makokha A. Nutrition status and associated factors among children in public primary schools in Dagoretti, Nairobi, Kenya. Afr Health Sci. 2013;13(1):39-46.

29. Srivastava A, Mahmood SE, Srivastava PM, Shrotriya VP, Kumar B. Nutritional status of school-age children - a scenario of urban slums in India. Arch Public Health. 2012;70(1):8.

30. Choi HJ, Lee HJ, Jang HB, et al. Effects of maternal education on diet, anemia, and iron deficiency in Korean school-aged children. $B M C$ Public Health. 2011;11:870.

31. Mukherjee MR, Chaturvedi S, Bhalwar R. Determinants of nutritional status of school children. Med J Armed Forces India. 2008;64:227-231.

32. Raj A, Saggurti N, Winter M, et al. The effect of maternal child marriage on morbidity and mortality of children under 5 in India: cross sectional study of a nationally representative sample. $\mathrm{Br}$ Med $J$. 2010;340:b4258.

33. Kimani-Murage EW, Norris SA, Pettifor JM, et al. Nutritional status and HIV in rural South African children. BMC Pediatr. 2011;11(23): $11-13$.

34. Vitolo RM, Gama CM, Bortolini GA, Campagnolo PDB, Drachler ML. Some risk factors associated with overweight, stunting andwasting among children under 5 years old. J Pediatr (Rio J). 2008;84(3): 251-257.

35. Finlay J, Özaltin E, Canning D. The association of maternal age with infant mortality, child anthropometric failure, diarrhoea and anaemia for first births: evidence from 55 low- and middle-income countries. Br Med J. 2011;1(2):e000226.

36. Linnemayr S, Alderman H, Ka A. Determinants of malnutrition in Senegal: Individual, household, community variables, and their interaction. Econ Hum Biol. 2008;6(2):252-263.

37. Katona P, Katona-Apte J. The interaction between nutrition and infection. Clin Infect Dis. 2008;46:1582-1588.

38. Herrador Z, Sordo L, Gadisa E, et al. Cross-sectional study of malnutrition and associated factors among school aged children in rural and urban settings of Fogera and Libo Kemkem districts, Ethiopia. PLoS One. 2014;9(9):e105880.

39. Ministry of Health. National Five-year Strategic Plan for Malaria Prevention and Control in Ethiopia, 2006-2010. Addis Ababa: Ministry of Health; 2006.

40. Gobena T, Berhane Y, Worku A. Low long-lasting insecticide nets (LLINs) use among household members for protection against mosquito bite in Kersa, Eastern Ethiopia. BMC Public Health. 2012;12:914.

41. Central Statistical Agency. The 2007 Population and Housing Census of Ethiopia: Statistical Report for Oromia Region. Addis Ababa: Central Statistical Agency; 2007.

42. Friedman JF, Kwena AM, Mirel LB, et al. Malaria and nutritional status among pre-school children: results from cross-sectional surveys in Western Kenya. Am J Trop Med Hyg. 2005;73(4):698-704.

43. Kang H, Kreuels B, Adjei O, Krumkamp R, May J, Small DS. The causal effect of malaria on stunting: a Mendelian randomization and matching approach. Int J Epidemiol. 2013;13(42):1390-1398.

original research, basic science, clinical \& epidemiological studies, reviews and evaluations, guidelines, expert opinion and commentary, case reports and extended reports. The manuscript management system is completely online and includes a very quick and fair peer-review system, which is all easy to use. 